\title{
The Use of Brainstorming Strategy Among Teachers of Arabic for Speakers of Other Languages (ASOL) in Writing Classes
}

\author{
Ibrahim ALRababah ${ }^{1} \&$ Luqman Rababah ${ }^{2}$ \\ ${ }^{1}$ Language Center, University of Jordan, Jordan \\ ${ }^{2}$ School of Arts and Languages, Jadara University, Jordan \\ Correspondence: Luqman Rababah, School of Arts and Languages, Jadara University, Irbid, Jordan. P. O. BOX \\ 733, Postal Code 20110, Jordan. E-mail: Rababah80@gmail.com
}

\author{
Received: August 26, 2018 Accepted: November 8, 2018 Online Published: December 27, 2018 \\ doi:10.5539/ijel.v9n1p15 \\ URL: https://doi.org/10.5539/ijel.v9n1p15
}

\begin{abstract}
Although brainstorming strategy is not a new concept, the practice is relatively new in the Arab region, especially, in Jordan, where the old approaches are still widely used. This qualitative study examined the attitudes of Arabic language lecturers at Language Center, University of Jordan towards utilizing brainstorming in their instruction. With the help of convenience sampling, ten lecturers were selected to participate in the study. To reach a clear understanding of this issue, the study utilized a qualitative design and semi-structured interviews and observations were used as a tool to collect the data. The findings revealed that the attitudes and the actual use of brainstorming strategy by ASOL lecturers in their instruction were generally positive. A key recommendation of the study is that further research needs to be conducted into the reasons why some instructors opt not to use brainstorming strategy in their instruction.
\end{abstract}

Keywords: brainstorming, Arabic language, writing, ASOL, language center

\section{Introduction}

Brainstorming is among the most effective ways for generating ideas, allowing the writer to determine the most optimum idea that he/she is utilizing for problem solving (Baumgartner, 2006). Brainstorming strategy is one of the most important strategies for provoking creativity and solving problems in the educational field (AlMutairi, 2015). Brainstorming is a conference method wherein a group tries to determine solutions for a particular problem by gathering ideas at one time. Hence, brainstorming maximizes the number of ideas that relate to a particular area of interest and the methods through which new ideas are generated. Brainstorming is considered as part of problem solving which entails, generation of new ideas without judgment and it is the development of a state of mind to solve problems by free association of various ideas/concepts.

As such, University of Jordan (UoJ) has placed fostering students' abilities at the top of its priorities list. UoJ has attempted to align it schools with ongoing educational developments of the $21^{\text {st }}$ century, which is evident from its launch of educational reform initiatives. UoJ through the represented Language Center (LC), has been paying close attention to new techniques/strategies in education in the general sense, and brainstorming in particular with a stress on writing skills.

However, despite the best efforts expended by the UoJ in developing and encouraging new strategies and despite several studies conducted internationally to find out the impact of brainstorming strategy on writing (Al-Qarni, 2011; Rababah \& Melhem, 2015; Rababah, Alshehab, \& Melhem, 2018; Shorofat, 2007), research on brainstorming strategies in an Arab context is scarce compared with that done in Western countries (Ibnian, 2011; Shorofat, 2007). Even those previous studies conducted in the Arab context were not in an Arabic language context. Thus, researchers in the region including (Al-Qarni, 2011; AlMutairi, 2015) and in Jordan including (Al-khatib, 2012; Ibnian, 2011; Rababah, Mohamed, Jdaitawi, \& Melhem, 2013; Rababah \& Melhem, 2015; Shorofat, 2007) have requested that additional studies should address the issue. In short, most of these studies were not carried out in either the Arabic Language field or in writing (Rababah \& Rababah, 2017; Rababah et al., 2013; Rababah \& Melhem, 2015; Shorofat, 2007). In other words, studies dedicated to brainstorming in writing are lacking generally. Thus, based on the issues discussed above, this current study identifies the following as a problem statement. 
1) Even though the UoJ has launched several initiatives and suggested the development of a curriculum based on developing Language skills including writing, creativity and problem solving, studies have shown that students still perform poorly in their creativity in writing (Al-Faoury \& Khwaileh, 2014; Ibnian, 2011; Rababah, 2018; Shorofat, 2007).

2) Researchers have attributed students' levels in writing skills to the strategies and techniques instructors have adopted (Al-Gomoul, 2011; Dweik \& Abu-Irmies, 2015; Dweik \& AL-Shallakh, 2015; Ibnian, 2011; Rababah \& Melhem, 2015; Rababah \& Almwajeh, 2018).

3) Despite seemingly countless studies addressing brainstorming, most of these studies were not in the Arabic Language context. In other words, studies dedicated to brainstorming in writing are lacking in the region (Al-khatib, 2012; Al-Qarni, 2011) and specifically in the Jordanian context (Ibnian, 2011; Rababah \& Rababah, 2017; Rababah et al., 2013; Rababah \& Melhem, 2015; Shorofat, 2007).

Thus, this justifies the present study's investigation of the usage of brainstorming strategy through interviews and observations, the present study attempts to explore brainstorming strategies and techniques to enhance the students' writing in Arabic Language. The present study investigates students' writing in Jordan and calls for the answers to the following research questions:

1) What brainstorming strategies and techniques are utilized in the classrooms to improve the students' ASOL writing?

2) How do ASOL lecturers employ brainstorming strategies and techniques in writing classes?

\section{Literature Review}

Brainstorming is among the many effective ways to create ideas, which allows the writer to determine the most optimum ideas that he/she can create for solving the problem (Jdaitawi, Ishak, Taamneh, Gharaibeh, \& Rababah, 2011). It also enables not just one participant but a group of participants to take part in the activity. According to Osborn (1953), brainstorming is a conference method wherein a group tries to determine solutions for a particular problem by gathering ideas at one time. Hence, brainstorming maximizes the number of ideas that relate to a particular area of interest and the methods through which new ideas are generated.

Several approaches have been proposed for teaching writing. In this respect, Kroll and Sunderman (2003) refer to the process approach as an umbrella term for several kinds of writing courses. Their viewpoint encapsulates the fact that student writers take part in writing tasks via a cyclical method as opposed to a single-shot method. According to Kroll and Sunderman (2003) "Writers are not expected to produce and provide complete and accurate responses to their writing tasks without going through different phases such as drafting and receiving feedback on their work from peers or instructors, and text revision" (p. 110). Thus, the process approach focuses on various activities taking place in the classroom that facilitate development of language use. Such activities are brainstorming, group discussion and re-writing (Kroll \& Sunderman, 2003). The Process Approach Model comprises eight phases (Vanessa, 2004) beginning with the first stage, which is brainstorming. Brainstorming refers to the idea generation and discussion. Students could discuss the required qualities to perform a specific job.

This is followed by the second stage, which entails planning and structuring. In this stage, students exchange their ideas and transform them into note form, after which they consider and judge the ideas in terms of quality and relevance. The third stage involves mind mapping in which students organize ideas into what is known as the mind map, spider gram, or linear form. This stage assists in developing the hierarchical linkage of ideas, which is necessary for text structure. The fourth stage involves the writing of the first draft in which students write the first draft in the class in pairs or groups. The fifth stage is feedback, and this stage entails the exchange of drafts, in a way by which students become the readers of their peer's work. When students respond as readers, they become aware that a writer is generating something that can be read by someone else, and, as such, they can make improvements on their own drafts. The sixth stage involves the editing process in which drafts are returned to the writers and improvements are made according to peer feedback. The seventh stage is the final draft, wherein the final draft is written. This is followed by eighth stage in which instructors evaluate and provide their feedback to students. 


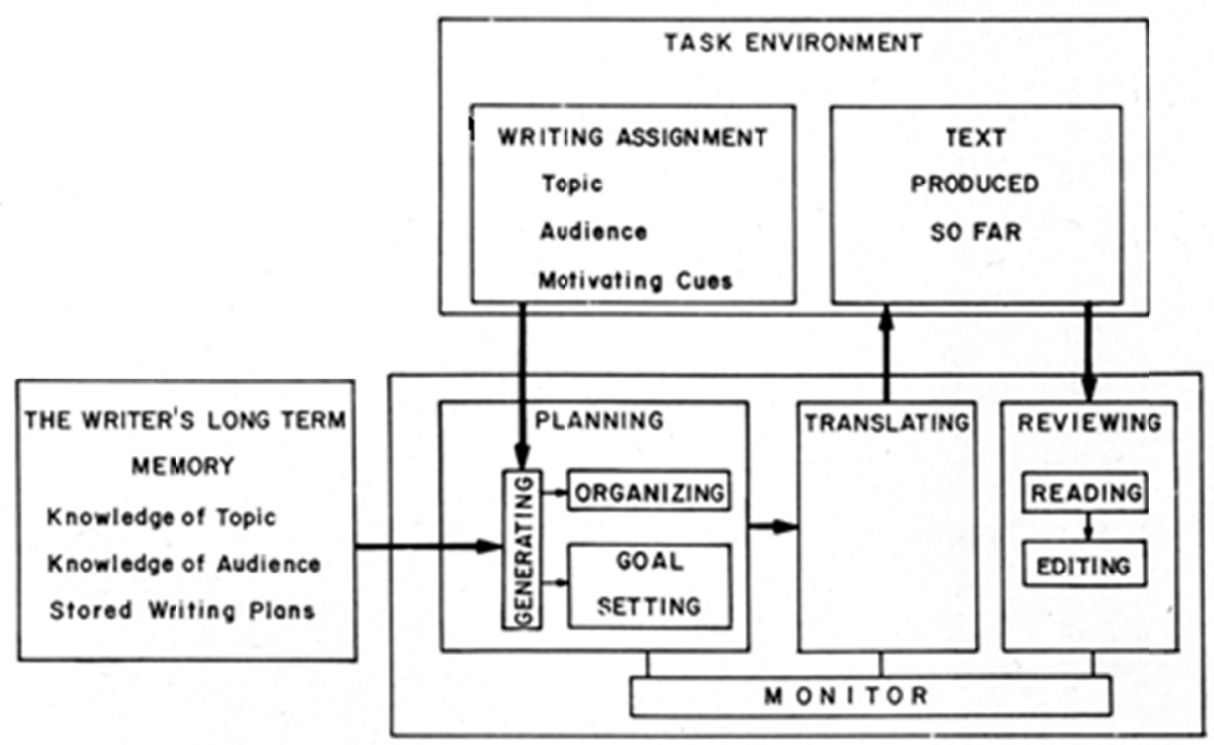

Figure 1. Flower and Hayes's model of creativity and writing. Taken from "A cognitive process theory of writing," by Flower and Hayes, 1981, College Composition and Communication, 32(4), 370

Flower and Hayes's (1981) model posits that the environment in which writing occurs and the writer's experience both form the context in which writing is conducted. Also, the writing process requires planning, translating, and reviewing. The planning process entails the generation of ideas, the organization of ideas and the setting of goals while translating entails language generation aligned with the idea generation drawn from writer's memory. Although an individual who lacks creativity can manage limited ideas, this limitation restricts the process and planning and eventually leads to an incomplete or confined writing process.

People often think of planning as the fact of determining how to get from here to there through making a detailed plan, Flower and Hayes's (1981) model uses the term planning much more broadly, and writers are seen as forming an internal representation of the knowledge to be used in writing. The other phases of the planning stage of the Hayes and Flower writing model include organizing and goal setting. Organizing involves choosing the subject matter retrieved by means of the generating process and structuring that subject matter into writing. The process includes structuring information in a cohesive, coherent manner, through knowledge via long-term memory and the task environment for the documentation (Flower \& Hayes, 1981). While organizing, writers structure their thoughts.

The other strategy of planning is goal setting. In goal setting, ideas from the generating process are used to assess the text to meet specified the goal. Goal setting entails conveying ideas and information, through the information gained by means of knowledge provided by long-term memory and task environment for the documentation. Setting goals makes people develop plans by thinking about the method or means by which they will achieve their goal. As their goals alter through several iterations, they will re-organize and adjust plans to fit their deepening understanding of the task at hand. Brainstorming is one strategy for idea generation (Chien, 2008). Students keep generating ideas on the topic they have initially identified; generating a thesis idea includes retrieving relevant information from long-term memory.

Sometimes this information is so well developed and organized in memory that the writer is essentially generating standard written English. After each idea is created, they return to the writing topic. In the model, the second part of the writing process is the act of composing that is referred to as-translating. This is when writers actually put their ideas into visible language, an activity through which the writer transforms ideas from the linear or hierarchic plan into sentences (Flower \& Hayes, 1981). Flower and Hayes help cast light on the different sub-skills of the actual strategies that writers might have to put into practice collectively. Second, the model establishes interdisciplinary links among composition studies, cognitive science and psychology. Finally, the model creates the prospect of writing process research that might lead to improvement in composition instruction. It helps change views about the teaching of composition. Writing is tough work, and to write well, a writer must self-regulate and monitor the intricate cognitive processes. 
Baumgartner proposed (2002) seven steps for brainstorming which are invaluable for teaching and learning in traditional education. These are presented in Figure 2.

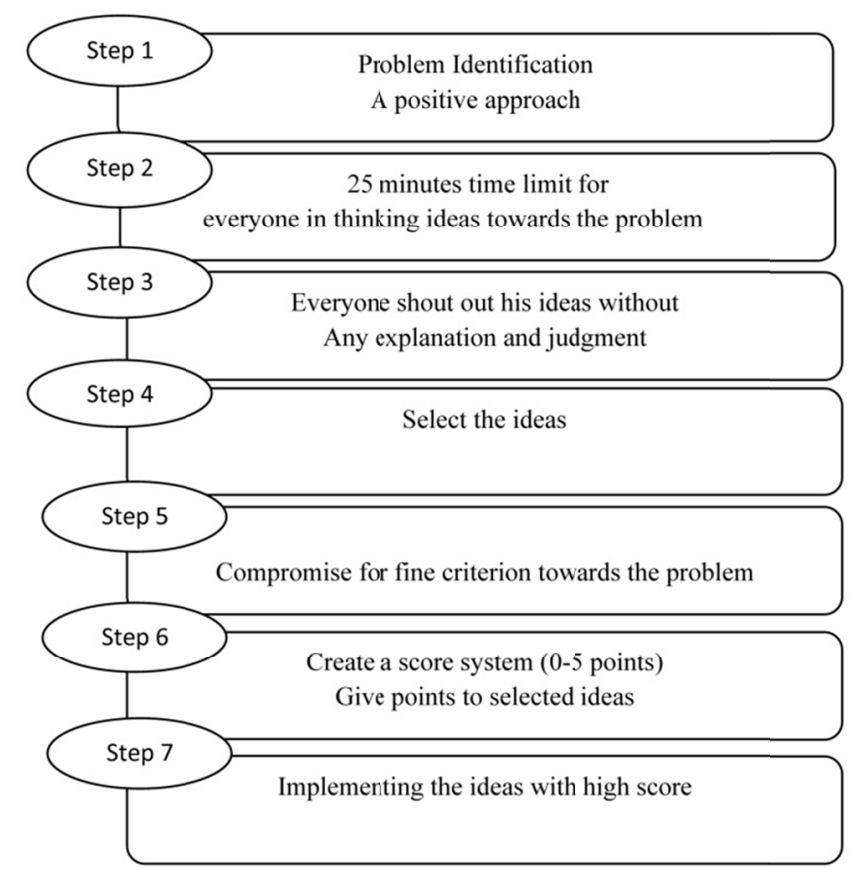

Figure 2. Brainstorming exercise adopted from (Baumgartner, 2002)

Step one entails the teacher requesting students to acknowledge the problem in a positive manner and to note a problem keyword for everyone to identify with it. In this step, there is no need to limit the problem (Baumgartner, 2003). This is followed by step two where students are given 25 minutes to think about the problem. This step prohibits the criticism of ideas, and encourages the creation of a warm and relaxed environment among participants. In the next step (step four), the teacher encourages learners to choose five ideas with their agreement. The members of each group must reach a consensus concerning the five criteria to judge which idea is the most optimum solution to the problem. This is followed by step six where a score system (from 0-5) is employed to by each to the ideas provided. Finally, the idea with the high score is adopted. Brainstorming has its advantages and these include, the easy facilitating of discussion through the above steps and the teacher's contribution may be provided as needed.

\subsection{Empirical Studies}

Several studies have been conducted to find out the impact of brainstorming strategy creativity and writing (Al-khatib, 2012; Al-Qarni, 2011; Ibnian, 2011; Rao, 2007; Shorofat, 2007). Al-Qarni (2011) carried out a study examining brainstorming strategy effectiveness in promoting creative thinking of $3^{\text {rd }}$ intermediate students in Saudi Arabia. The purposeful sampling was randomly chosen which comprised 115 male and female students. The results showed a statistically significant difference between the means of the groups on the test. In the Jordanian context, Al-Khatib's (2012) study investigated the effect of using the brainstorming strategy in developing creative problem-solving skills among female students at Princess Alia University College in Amman. The sample comprised 98 female students who were distributed into two classes. The first group was the experimental group of 47 students who were taught thinking skills through the brainstorming strategy during the academic year 2010-2011. The second was the control group totaling 51 students who were taught using traditional methods. The instrument used in this study was the Torrance Creative Thinking Test. The findings of the study showed statistical significant differences at $p \leq .05$ between the experimental group and the control group in the total score and the sub-scores of creative thinking. The results indicated the effectiveness of using brainstorming strategy in developing creative thinking skills.

Similarly, Ibnian (2011) aimed at investigating the effect of using the brainstorming technique on developing first secondary grade students' essay writing skills in EFL. The study attempted to answer the following questions: 1-What are the essay writing skills needed for first secondary grade students in EFL? 2- What is the 
effect of using the brainstorming technique on developing first secondary grade students' essay writing skills in EFL? Tools of the study included a checklist to identify the essay writing skills needed for first secondary grade students in EFL as well as a pre- post essay writing test and its scoring scale. Results revealed the effect of using the brainstorming technique on developing first secondary grade students' essay writing skills in EFL.

Additionally, Shorofat (2007) examined the effect of utilizing brainstorming and synectics developing female ninth graders' creative writing skills as well as their attitudes towards writing. The study sample comprised 132 students studying in Zarqa Governorate (Jordan) Schools, categorized into one control group and two experimental groups. The control group used traditional methods, one experimental group used brainstorming, and one group used synectics. He employed a pre-test on the three groups and then taught the students for five weeks. The results of the post-test revealed that both brainstorming and synectics usage were more effective in developing the creativity in writing skills of the students compared to the traditional method.

Internationally, Rao's (2007) study examined the impact of training in brainstorming on the students' writing performance and perceptions. Those students who were instructed the strategy of brainstorming comprised of two classes of sophomores in a Chinese University. The pre and post-study writing performance of the students was assessed and compared with a third group that were not instructed on brainstorming but was requested to complete the pre and post-study task. The article went on to provide a description of the provided instruction and the impact of brainstorming instruction. Based on the data, explicit instruction of brainstorming strategy displayed a measurable impact on the students' performance of writing. In addition, the attitudinal survey showed that the students had a positive perception of the brainstorming strategy. The researcher suggested that EFL instructors in universities/colleges shift from the product-based approach towards a process-focused approach in their writing teaching as the second approach may assist in encouraging students' thinking and creating ideas for a writing assignment.

Despite seemingly countless studies addressing brainstorming, most of these studies were not in the Arabic Language context. In other words, studies dedicated to brainstorming in writing are lacking in the region (Al-khatib, 2012; Al-Qarni, 2011) and specifically in the Jordanian context (Ibnian, 2011; Rababah \& Rababah, 2017; Rababah et al., 2013; Rababah \& Melhem, 2015; Shorofat, 2007).

\section{Methods}

The present study used a qualitative approach to obtain data from LC lecturers to determine the answers to the research questions. The qualitative approach is useful to help the researcher to explore social or human problems and then build a complex picture, analyze words, report detailed information and conduct the study in a natural setting (Creswell, 2013; Denscombe, 2014).

\subsection{Setting and Participants}

In the context of the present study, LC is at UoJ in Amman where the researchers collected data from participants prior to the study by means of a convenience sample selected from the population. The LC is considered one of the leading institutions in the region teaching Arabic to Speakers of Other Languages (ASOL). Since its inception in 1979, the LC started offering Arabic courses for Speakers of Other Languages. It has taught Arabic to thousands of students from all parts of the world (Dweik \& AL-Shallakh, 2015). The LC offers six levels, and may offer nine levels based on the results of a placement test, of intensive Arabic throughout the year (Rababah \& Rababah, 2017). A total of ten Arabic language instructors from LC were involved in this study during the academic year 2016/2017. The instructors hold Ph.D. and M.A. degrees in Arabic and in teaching Arabic as a second language. Instructors were required to undergo extensive classroom and on-the-job training. LC put an emphasis on hiring the best instructors for programs results in not just superior program outcomes, but it keeps our students coming back (Dweik \& AL-Shallakh, 2015).

\subsection{Sampling}

Convenience sampling is utilized in research in case the researcher is desirous of obtaining a reasonable approximation of the truth, and it provides useful information (Creswell, 2013). Creswell (2013) claimed that convenience sampling makes it easy for the researcher to select participants, as they are available and willing. Therefore, in the current study, the researcher selected participants because they were willing and available to be studied. The sample comprised ten ASOL instructors. For reasons of confidentiality in this research, the instructors are identified only through codes.

\subsection{Data Collection}

This study employed two data collection instruments, namely, interviews and observations. The present study employed the semi-structured interview because, according to Creswell (2013). semi-structured interviews have 
several advantages, including enhancing the accuracy of the individual's responses, enabling the informant's free responses, and enabling the researcher to follow up upon ideas, to investigate, develop and clarify answers while the interview is going on. In addition, semi-structured interviews also enable the researcher to develop his or her own interview guide without having to strictly follow question lists word for word. Moreover, the current study employed a non-participant observation tool. A non-participant observation occurs when the observer visits a site and records notes without becoming involved in the activities of the participants. In order to check the credibility and trustworthiness of the study, member check was carried out in this study by presenting the collection of data from the classroom observations and interviews. Participants were able to access their audio-taped interviews and the written transcripts of the interviews, classroom observation guidelines and field notes.

\subsection{Data Analysis}

Qualitative data is in the form of words spoken or return, visual images observed or produced (Creswell, 2012; Denscombe, 2010). Accordingly, in the present research, the data was collected through observations and interviews. Qualitative data analysis requires the appropriation of meaning to text and images in order to answer the research questions. In this regard, Creswell (2012) recommended six steps that a researcher uses as a guideline in collecting, analyzing and interpreting qualitative data. These six steps are; preparing and organizing data, exploring and coding database, describing findings and forming themes, representing and reporting findings, interpreting the findings. First, in preparing and organizing data, at an early stage in the qualitative analysis, the researcher organized the data into file folders. Second, exploring the data and developing codes were carried out.

The researcher used preliminary exploratory analysis that is applicable to qualitative research, comprising exploration to obtain a general sense of that data, generating ideas, thinking about the organization of the data, and considering whether more data was needed. The researcher then analyzed the text. In qualitative research, this process begins with the coding of the data. Coding is the process of segmenting and labeling text to form descriptions and broad themes that emerge from the data. The researcher used coding to make sense out of text data, to divide it into text or image segments, to label the segments with codes, to examine codes for overlap and redundancy, and to collapse these codes into broad themes. Narrowing data into a few themes is an inductive process, involving proceeding from the narrower themes to broader themes. Also, in this process the researcher selected specific data to use and disregarded other data that did not specifically provide evidence related to themes.

After the initial reading and coding of the data, the researcher started using the established themes. When these themes or categories are similarly coded, they are aggregated together to form a major idea in the database and form a core element in the qualitative data analysis (Cresswell, 2013). In the initial iteration, the researcher found several codes. In subsequent analyses, the researcher reduced these codes into a few major themes through the process of eliminating redundancies as previously suggested (Creswell, 2013; Denscombe, 2010). After that, the researcher developed major themes and sub-themes in the current study. Once the major themes and minor themes are established, the researcher represents them and reports the findings by displaying those themes visually via tables that augment the discussion. The primary form for representing and reporting findings in qualitative research is a narrative discussion. In this discussion, the researcher summarizes, in detail, the findings from his/her data analysis.

\section{Results}

The present study examined the usage of brainstorming strategy through interviews and observations, the present study attempts to explore brainstorming strategies and techniques to enhance the students' writing in Arabic Language. The current study investigates students' writing in Jordan and calls for the answers to the following research questions:

1) What brainstorming strategies and techniques are utilized in the classrooms to improve the ASOL students' writing?

2) How do ASOL lecturers employ brainstorming strategies and techniques in writing classes?

\section{Question One: What brainstorming strategies and techniques are utilized in the classrooms to improve the} ASOL students' writing?

To examine the strategies and techniques that instructors adopted and to determine the answer to the second research question, the researcher used interviews. Eight participating instructors provided their feedback on how they used brainstorming for the promotion of students' writing in Arabic language. Some of their responses are provided in this section. To begin with, TD stated that he employed brainstorming during writing classes. He 
believed that this technique allowed students to enhance their creativity in writing (TD, Interview, November 1, 2016). Another instructor, TC, preferred brainstorming in group discussions. He claimed that he used brainstorming as it could enable more than one student to participate. According to him, Brainstorming is one of the components of problem solving that entails the production of new ideas without judgment and it originates from an optimal problem solving state of mind brought about by the interaction of difference concepts and idea (TC, Interview, November 7, 2016). Apparently, brainstorming was the most common pre-writing activity employed to assist students in gathering their thoughts prior to writing. This method was among the ones instructors most often mentioned in their interviews.

Specifically, TF related that prior to writing: The students were required to answer questions to brainstorm ideas and to prepare them for writing. They were then told to list phrases and single words which they could use later. The process was different for different writing genres; for different writing topic, they listed opinions, arguments, facts, questions or components, or a combination of each. The students were advised to write with autonomy (TF, Interview, and November 13, 2016). Another teacher, TJ, who had 15 years of teaching experience, spoke about how he initiated brainstorming in his class. He related that he used brainstorming frequently in his assignments written in class. Therefore, brainstorming occurred often when students begin talking about paragraph writing or similar tasks. He stated: Upon receiving the topic, brainstorming could ensue information on how to begin writing, the writing format and content is passed from one individual to another. Accordingly, brainstorming is conducted before beginning any kind of paragraph writing (TJ, Interview, November 27, 2016). However, not all the participating instructors were in favour of brainstorming. According to TI, I always depended on old strategies when it used to come to teaching writing to students, as I believed that new strategies are often unsuccessful and ineffective. ... From my experience, giving students free discussion and without criticizing them is not fruitful for coming up with new ideas (TI, Interview, November 25, 2016).

\section{Question two: How do ASOL lecturers employ brainstorming strategies and techniques in writing classes?}

Through observations, the instructors were observed in their classrooms to determine the strategies they utilized, and these observations led to the conclusion that instructors generally employed brainstorming strategy. Brainstorming is a commonly used pre-writing activity that assists in generating ideas. These ideas are then noted and organized. The observations of the instructors showed that seven instructors used the strategy in their writing classes. For instance, TD was observed employing this strategy during teaching. In one instance, the task assigned to the students was to write a thank-you note in class, and the researcher observed TD leading the students' brainstorming activities. He asked them to come up with five people to whom they would like to write a thank-you note. Following the students sharing and discussing ideas, TD asked them to think of another person to add to their list to extend the brainstorming activity. He then asked the students to list their ideas, phrases, and expressions, which they thought they could use in the writing tasks (TD, Observation1, December11, 2016).

Another participant, TJ was observed helping students to brainstorm topics through questioning them and guiding them in the process (TJ, Observation2, December16, 2016). Some students claimed that they had nothing to write about to which TJ replied by encouraging through multiple questions just to get the students started with their writing tasks. TH was observed beginning his writing class by clarifying the topic for the day, which was the weather. The students were then requested to supply words relating to the topic, to which they replied with words like temperature, rain, seasons, cold, mild, cloudy, hot, and stormy. TH accepted the ideas, even the incorrect ones that the students provided such as mountains (TH, Observation2, December 17, 2016). Another teacher, TF requested that his students to come up with ideas regarding the picture he showed them about making a hotel reservation, to which the students replied with the words double-room, single room, reserve, heater, balcony, how much, and how many. The picture used in this case served as mental touchstone and inspiration for the students' imagination (TF, Observation 3, December 20, 2016). To sum up, brainstorming was used as a pre-writing activity by participating instructors as was noted in their attempts to help students organize their thoughts prior to actual writing. The participating instructors were observed employing these strategies in their actual classroom practice.

\section{Discussion}

This qualitative study examined the attitudes of Arabic language lecturers at language center, university of Jordan towards utilizing brainstorming in their instruction. With the help of convenience sampling, ten lecturers were selected to participate in the study. To reach a clear understanding of this issue, the study utilized a qualitative design and semi-structured interviews and observations were used as a tool to collect the data.

During the interviews, eight of the ten participating instructors provided feedback on how they used brainstorming to promote the development of students' writing creativity in EFL. Generally, their views were 
positive about using this strategy to generate ideas, and most of the instructors used brainstorming, which has long been considered to be an important strategy for student learning (Osborn, 1957). The observations showed that seven instructors actually used the strategy in their writing classes. One noted that this strategy allowed students to enhance their creativity in writing. Instructors used many tactics with respect to brainstorming to help improve creativity and to produce ideas that could be used later in problem solving or other creative processes. One key to the success of the process is that no evaluation or judgment is made of the ideas as they are being generated. Most of the instructors in this study had the objective of generating as many ideas as possible related to the specific topic or question. During the interviews and observations, instructors said that no criticism, evaluation, judgment, or defence of ideas was used during the brainstorming sessions. The idea was to generate as many ideas related to the topic as possible in the time allowed, and evaluation, judgment, and selection of ideas were reserved for subsequent sessions. For example, teacher TH was observed accepting all ideas, even the wrong ones that the students provided on the topic of climate.

Furthermore, freewheeling in the brainstorming sessions was welcomed and encouraged. Members were asked to voice any potential solutions that they could think of, no matter how outrageous or impractical they seemed. Instructors believed that it was easier to tone down an idea or to select an appropriate one later than it was to think up new and creative possibilities. In this study, some students claimed that they had nothing to write about to which teacher TJ replied by using multiple questions to get the students started with their writing tasks. Moreover, quantity is more desired than quality during brainstorming strategy. In this study, instructors encouraged group members to contribute as many ideas as they could think of. The greater the number of ideas generated, the more likely it is that several useful ideas will emerge. For example, teacher TF requested that his students come up with ideas about the picture that he showed them regarding hotel reservations. However, few instructors did not believe that the rule — not to criticizell would actually inhibit creativity. For example, teacher TI depended on old strategies in teaching writing to students, as he believed that new strategies were often unsuccessful and ineffective. He believed that giving students free discussion without criticizing them is not fruitful for generating new ideas. On a negative note, the observation results showed a discrepancy between a response of a teacher in the interviews and his actual employment of the strategy with respect to the use of brainstorming strategy in writing classes. Eight instructors interviewed reported using the sub-themes of brainstorming but only seven were actually observed using brainstorming.

The brainstorming strategy had many advocates who, however, espouse different techniques. For example, Flower and Hayes (1981) presented a heuristic strategy for analytic writing comprising both traditional rhetorical strategies, such as brainstorming and problem-solving strategies (Piirto, 2008). Brainstorming is one part of the process of generating ideas and is seen as part of the planning phase in the Flower and Hayes's (1981) model. Flower and Hayes (1981) asked writers to compose aloud while writing and they paid particular attention to the ways in which writers set up and solved problems as they wrote. Nickerson (1999) and Piirto (2008) mentioned multiple idea generation techniques that included brainstorming and divergent thinking methods and other instructional approaches to increasing creativity. Based on observations and interviews conducted with the instructors, they believe that using brainstorming could improve students' EFL writing. They opt for using brainstorming particularly in group discussions.

In literature, authors (Al-khatib, 2012; Al-Qarni, 2011; Ibnian, 2011; Rao, 2007; Shorofat, 2007) established the impact of brainstorming in developing creative writing skills of students. The interviewed instructors explained the role of brainstorming in their classrooms and it seems that brainstorming is a widely used pre-writing activity that helps students to gather their thoughts concerning what they are going to write about. For example, in our observations, we noted TJ helping students to brainstorm topics by asking them questions and driving the process. When some students worried about what to write, TJ encouraged them through questions to get them started. Brainstorming also appeared to be the most widely used pre-writing activity by instructors in an attempt to assist students in organizing their thoughts as we evidenced in my observations.

\section{Conclusion and Recommendations}

The concluding remarks about this study are strongly driven from the knowledge that gained about teaching writing to Jordanian students in general, and using the writing strategies/techniques (e.g. brainstorming) as tools to improve their writing development. No student is born a writer as every student may be made capable of becoming an excellent writer with due practice and time. Effective writing startegies cater to the talent and development of individual writers and encourage ongoing writing as they begin to build confidence about their writing abilities. ASOL writer's success could contribute to the roles of instructors in employing suitable strategies, methods and approaches. As teaching regular students require skills and efforts, teaching ASOL students will surely need added time and effort in addition to the skills. Hence, it is important for ASOL 
instructors to acknowledge that becoming an effective writing teacher requires the creation of a conducive climate for students to have the freedom and autonomy to express their ideas and thoughts.

It is important for ASOL instructors to make their students comfortable and at ease during writing as the core reason behind it is enjoyment and productivity. Student's writings should be valued and not criticized by either instructors or peers. The present study employed a distinct and practical look at how Arabic writing can be promoted in the classroom. Nevertheless, I found the challenge worth taking, owing to the necessity to provide an insight into reality as it takes place in a natural environment. Accordingly, this study provides and examines the role of brainstorming strategy in writing instruction. Encouraging students to write via creative strategies provides various learning opportunities. The instructors incorporates in the process like brainstorming to assist students' development in writing.

It is hoped that information in this study will provide guidance to future instructors of writing as they attempt to continuously enhance their students' writing skills. Instructors in this study can be role models to other instructors in their use of various research-bases strategies to assist their students in becoming creative writers. As stated by Hillocks (1984), the most common way of teaching writing is not necessarily effective and instructors should think of ways to go beyond the present instruction and actually introduce what research and anecdotal evidence has proved in their classrooms. Instructors could make use of the findings in this study to modify their writing classes and use group instruction. Over time, they could gradually increase group instruction and the types of writing being taught. From this study's findings, instructors could modify their writing instruction by providing their students more leeway and autonomy to get their ideas on paper and not worry too much about the correctness of their grammar and spelling. This could be made possible by discussing the errors after the composition of drafts through one-on-one sessions with the teacher. In this study, the instructors interviewed managed to improve their students' writing by embarking on strategies that have been proven effective for the ASOL environment. Other instructors should follow suit. As mentioned earlier, studies dedicated to brainstorming in writing and its strategies in the context of Jordan are still few and far between (Ibnian, 2010, 2011; Rababah et al., 2012, 2013). Hence, this study recommends the following for future research to minimize the gap in literature; Future studies are encouraged to look into the reasons behind why some instructors opt not to use brainstorming strategies in their instruction as this could provide program directors with the initiative to resolve the issue and support instructors in improving their writing instruction and to engage their students in helpful activities.

\section{References}

Al-Gomoul, M. (2011). Teaching and assessing writing strategies for secondary school students and investigating teachers' and students' attitudes towards writing practice. International Journal of Educational Sciences, 3(1), 25-37. https://doi.org/10.1080/09751122.2011.11890006

Al-khatib, B. A. (2012). The effect of using brainstorming strategy in developing creative problem solving skills among female students in Princess Alia University College. American International Journal of Contemporary Research, 2(10), 29-38.

AlMutairi, A. N. M. (2015). The Effect of Using Brainstorming Strategy in Developing Creative Problem Solving Skills among Male Students in Kuwait: A Field Study on Saud Al-Kharji School in Kuwait City. Journal of Education and Practice, 6(3), 136-145.

Al-Qarni, F. (2011). Measuring the effectiveness of using brainstorming strategy in developing creative thinking in science among third intermediate students in Qurayyat city. Unpublished Master Thesis. Al-Balqa Applied University. Salt. Jordan.

Baumgartner, J. (2003). The step by step guide to brainstorming. Retrieved from http://www.Jpb.com/creative/brainstorming.html.

Chandler-Olcott, K., \& Hinchman, K. A. (2005). Tutoring adolescent literacy learners: A guide for volunteers. Guilford Press.

Creswell, J. W. (2013). Research design: Qualitative, quantitative, and mixed methods approaches. Sage publications.

Denscombe, M. (2014). The good research guide: for small-scale social research projects. McGraw-Hill Education (UK).

Dweik, B. S., \& Abu-Irmies, A. J. (2015). Learning Arabic Culture By Speakers Of Other Languages. International Journal of Education Learning and Development, 1, 109-119. 
Dweik, B., \& AL-Shallakh, M. (2015). Teaching Arabic for Non-Natives in Jordanian Public Universities: Difficulties and Solutions. American Journal of Educational Science, 1(3), 52-59.

Flower, L., \& Hayes, J. R. (1981). A cognitive process theory of writing. College Composition and Communication, 32(4), 365-387. https://doi.org/10.2307/356600

Ibnian, S. S. K. (2011). Brainstorming and essay writing in EFL class. Theory and Practice in Language Studies, 1(3), 263-272. https://doi.org/10.4304/tpls.1.3.263-272

Jdaitawi, T., Ishak, N., Taamneh, A., Gharaibeh, N., \& Rababah, M. (2011). The effectiveness of emotional intelligence training program on social and academic adjustment among first year University students. International Journal of Business and Social Science, 2(24).

Kroll, J. F., \& Sunderman, G. (2003). Cognitive processes in second language learners and bilinguals: The development of lexical and conceptual representations. The Handbook of Second Language Acquisition, 104-129. https://doi.org/10.1002/9780470756492.ch5

Nickerson, R. S. (1999). Enhancing Creativity. In R. J. Sternberg (Ed.), Handbook of Creativity (pp. 392-410). Cambridge, UK: Cambridge University Press.

Piirto, J. (2008). Rethinking the creativity curriculum: An organic approach to creativity enhancement. Mensa Research Journal, 39(1), 85-94.

Rababah, I., \& Rababah, L. (2017). Investigating Arabic to Speakers of Other Languages (ASOL) Lecturers' Attitudes towards Utilizing Flipped Classroom Instruction (FCI): A Qualitative Study at Jordanian Public Universities. International Education Studies, 10(7), 94-104. https://doi.org/10.5539/ies.v10n7p94

Rababah, L. (2018). An adapted version of torrance test of creative thinking (ttct) in efl/esl writing: a rubric scoring and a review of studies. International Journal of English and Education, 7(2), 128-136.

Rababah, L. M., Mohamed, A. H. Bin, Jdaitawi, M. T., \& Melhem, N. Z. B. (2013). The level of creativity in English writing among Jordanian secondary school students. Arts and Design Studies, 10, 25-29.

Rababah, L., \& Almwajeh, M, (2018). Promoting creativity in EFL/ESL writing through scaffolding strategy. International Journal of English and Education, 7(3), 148-160.

Rababah, L., \& Melhem, N. (2015). Investigation into Strategies of Creativity in EFL Writing in Jordan. Journal of Literature, Languages and Linguistics, 3(5), 14-25.

Rababah, L., Alshehab, M., \& Melhem, N. Z. B. (2018). Exploring the Factors that Hinder Jordanian Students in Developing Creativity in EFL Writing. International Journal of English and Education, 7(3), 161-170.

Rao, Z. (2007). Training in brainstorming and developing writing skills. ELT Journal, 61(2), 100-106. https://doi.org/10.1093/elt/ccm002

Shorofat, A. (2007). The effect of using the brainstorming strategy on developing ninth grade students' creative writings skills in Arabic language. Unpublished Ph. D. university of Jordan, Jordan.

Vanessa, S. (2004). Product and Process Writing; A Comparison. London, British Council Educational Service.

\section{Copyrights}

Copyright for this article is retained by the author, with first publication rights granted to the journal.

This is an open-access article distributed under the terms and conditions of the Creative Commons Attribution license (http://creativecommons.org/licenses/by/4.0/). 